\title{
Systematic analysis of digital reading studies in the digital age
}

\author{
Zuhal Çeliktürk Sezgin* \\ Faculty of Education, Burdur Mehmet Akif Ersoy University. Burdur, Turkey \\ ORCID: 0000-0001-7015-8426
}

Article history

Received:

20.03.2021

Received in revised form: 01.06 .2021

Accepted:

15.06.2021

Key words:

Digital reading;

Reading format;

Reading comprehension;

Digitalization has led to significant changes in reading like it does in almost every field. When traditional print reading is considered together with digital reading, it can be argued that digital reading differs from printed reading in many respects. Given the complex nature of reading, it is predictable that an in-depth examination of digital reading is needed. In this context, this research aims to determine the trends and prominent concepts/topics by examining the studies on digital reading in a systematic and holistic manner. In the research, peer reviewed articles related to the concept of digital reading indexed in the Web of Science database were analyzed. Data analysis methods such as content analysis, descriptive analysis and bibliometric analysis were used in the research. As a result of the research, it was seen that there was a significant increase in digital reading studies especially in recent years. It is also determined that digital reading studies are concentrated in developed countries. The data on the participants were also examined in the studies. Accordingly, it was identified that the highest number of studies took place at the K-12 level, and the participants generally had a lower-tomedium socioeconomic status. The sampled papers were also analyzed in terms of reading methods and it was seen that digital shared reading was used more than other reading methods. When the most commonly used variables, the most used concepts in the abstract sections or the most used keywords are examined, it is noticeable that the concept of reading comprehension comes to the fore. When the authors/references that received the most references in the field were analyzed, it was determined that OECD reports were referenced the most. In line with the findings obtained, results were discussed mutually with the literature and various inferences were made.

\section{Introduction}

Today, individuals live in a digital world engulfed by technology. With the proliferation of digital devices such as "computers, tablet computers and handheld devices" in our daily lives, screen-based reading replaces paper reading (Chen, Cheng, Zheng \& Huang, 2014). Technology and the internet are increasingly emerging as a basic life component. This may suggest that individuals of all ages may lose the balance in their digital or print reading preferences in favor of digital reading. With the widespread use of internet, computer and

\footnotetext{
* Correspondency: zuhalcelikturk@mehmetakif.edu.tr
} 
mobile tools in education, the use of hypertexts in education has become a common norm in primary schools (Karchmer, 2008). In fact, it can be said that digital screen technologies today replace paper-printed reading in both in-class readings and leisure readings (Støle, Mangen \& Schwippert, 2020). Such facilitation of access to digital tools can also lead to a change in traditional reading activities, especially in children or adults (Liu, 2005; Rideout, 2017).

Hayles describes reading as a neuroscientific phenomenon and also describes it as "a powerful technology with the ability to rearrange efficacy patterns in the brain" (Hayles, 2010, p.193). When this metaphor is evaluated together with real-life technology, it seems important to examine the components of the digital side of the reading concept (Liu, 2005) with a holistic view, which already has a very complex structure. Digital reading, however, requires the implementation of some strategies that are not included in traditional print reading (Liu, 2012). In addition, the act of digital reading may differ in cognitive processes where "brain activity, context, cognitive focus, multitasking, comprehension and speed" according to reading from printed paper (Cull, 2011) tend to change. This research aims to determine the trends and prominent concepts/topics in the relevant subject by examining the studies on digital reading in a systematic and holistic manner.

\section{Related literature: Paper based-screen based?}

Rapid developments in the digital world greatly affect teachers, children and reading education (Blanchard \& Farstrup, 2011, p.286). Although many people are continuously reading on screen with the help of various digital tools, researchers know relatively little about digital reading compared to print reading (Baron, 2020, p.117). With the increasing number of people using digital resources more widely and taking more time to read online, some changes have begun to be seen in reading practices and behaviors (Liu, 2012).

There are many studies comparing digital reading and traditional printed reading methods (Clinton, 2019; Delgado, Vargas, Ackerman, \& Salmerón, 2018; Haddock, Foad, Saul, Brown, \& Thompson, 2020; Golan, Barzillai \& Katzir, 2018; Loh \& Sun, 2019; Singer \& Alexander, 2017; Støle et al., 2020). These studies mainly focus on reading comprehension. Some of the studies carried out with different age groups and digital tools/media revealed that traditional print reading yielded more positive results against digital reading (Ackerman \& Salmerón, 2018; Clinton, 2019; Delgado et al., 2018; Golan et al, 2018; Mangen, Walgermo, \& Brønnick, 2013; Singer \& Alexander, 2017; Støle et al., 2020) while others did not find any significant difference between the two reading formats (Ackerman \& Goldsmith, 2011; Kerr \& Symons, 2006; Margolin, Driscoll, Toland \& Kegler, 2013; Porion, Aparicio, Megalakaki, Robert \& Baccino, 2016; Taylor, 2011). However, there are studies that report that digital reading provides more positive outcomes than printed reading (Aydemir, Öztürk, \& Horzum, 2013; Baron, Calixte, \& Havewala, 2017; Ji, Michaels, \& Waterman, 2014; Liu, 2005; Pinto, Pouliot, \& Cordón-García, 2014).

When the related field is examined in general in the context of reading comprehension and performance, it is noticeable that the studies in which printed reading outputs are higher or at similar levels compared to digital reading, is greater in number. Considering the advantages of digital reading materials, this situation becomes an issue to be analyzed. Digital reading has advantages such as interactivity relative to print reading, fast access to information and the availability of many media components (audio, visual, text, video) (Chen \& Chen, 2014), cost (Ji et al., 2014), "time spent on browsing and scanning, keyword spotting, one-time reading, 
non-linear reading, reading more selectively" (Liu, 2005), multi-tasking and convenience (Baron et al., 2017).

For readers with negative experiences with reading activities, digital reading may be more interesting (Tveit \& Mangen, 2014). Also, many educational institutions offer digital materials to their students through learning management systems or online platforms. This open educational resource movement can also highlight the use of digital reading materials (Baron et al., 2017). Based on all this, in this research it is aimed to examine the trends and prominent concepts related to digital reading studies holistically. However, the variables discussed in the digital reading studies were examined in this research and a map of the complex structure of printed reading and digital reading was tried to be revealed along with the reading comprehension variable. It is a fact that digital readings are increasing in today's world. As a result of this increase, the number of studies focusing on digital reading increased. In this context, the general aim of the research is to examine the studies on digital reading from a systematic and holistic point of view and to determine the relevant trends and prominent concepts/topics. For the purpose of the research, the following research questions were answered:

(1) Is there a growth trend of digital reading studies by year and citation numbers?

(2) What is the distribution of digital reading studies by country?

(3) What are the characteristics of the target participants in digital reading studies and the reported socio-economic levels?

(4) Which research method has been used more frequently in digital reading studies?

(5) What are the most researched reading methods-techniques-tools in digital reading studies?

(6) What are the most used variables (dependent-independent) in digital reading studies?

(7) What are the most used terms in the abstract sections of sampled papers?

(8) What are the most used author keywords in sampled papers?

(9) Which sources/authors are the most cited in the relevant literature?

\section{Methodology}

\section{Research design and inclusion criteria}

In this research, scientific peer reviewed articles related to the concept of digital reading indexed in the Web of Science (WOS) database were analyzed. Systematic literature reviews are a special methodology that finds, selects and evaluates existing studies, analyzes and synthesizes data, and reports with clear results on what is known and unknown in the findings (Denyer \& Tranfield, 2009, p. 671). Advanced search queries of the WOS database were used to determine the scope of the research and the most appropriate query for computer-aided bibliometric analysis was written. An expert's opinion was also consulted in the creation of the query. Within the scope of the research, TS= ("digital reading" OR "screen reading" OR "electronic reading" OR "monitor reading") AND ("student" OR "children") database search query was used to find the most appropriate results. The query was carried out at the level of title, keywords and summaries of the studies. No time restrictions were imposed in this study. However, some criteria have been set for determining the studies to be included in the research. First of all, only articles written in English were included in the research. In addition, the following criteria were added: the relevant study must be peer reviewed and have full-text access online. 


\section{Data collection and analysis}

Within the scope of the research, 68 articles were reached as a result of detailed scans carried out from the relevant database. The abstracts were examined, and non-related articles were excluded from the research, and 55 articles remained for review. In order to make the analyses, the full texts of the studies were examined based on the categories previously determined by the researcher. The categories were publication years and citation numbers, number of participants by country, participants, methods, reading type / method / technique / tools, and variables, respectively. Another field specialist was then asked to do the same. These analyses were encoded through an Excel document.

In addition, the authors of the related studies, the year of publication, country of publication, bibliography, abstract information and systematic categories of keywords are exported from the WOS database in Excel and tab-delimited (Win format)- (full record and cited references) format, making them ready for descriptive content analysis and bibliometric network analysis. VOSviewer software was used for the bibliometric network analysis section of the research. VOSviewer is a bibliometric networking and visualization software that uses text mining and interrelationship/union parameters (Van Eck \& Waltman, 2010).

Content analysis, descriptive and bibliometric analyses were used in the research. The data encoded within the scope of the research (categories, years and citation numbers, number of participants by country, participants, methods, reading type/method/technique/tools, variables) were analyzed with content analysis and descriptive analysis techniques and the results obtained were analyzed and presented. However, for bibliometric network analysis, VOSviewer software analyzed co-occurrences, bibliometric mapping (bibliometric coupling) and co-citation in the context of abstracts, bibliography and keywords. These analyses were carried out through the author and bibliography analysis units and presented by mapping.

\section{Reliability}

Within the scope of the research, categorical examination of the articles included in the analysis and encoding of the Excel form were carried out primarily by the author. A field expert was then asked to review and encode the articles. After both encoders completed their encoding, the reliability coefficient between encoders was examined to calculate the reliability of the research. Miles and Huberman (1994) formula were used to calculate the reliability coefficient. In this study intra-rater agreement between encoders were calculated as between the range of $86 \%$ and $98 \%$ for predefined categories. After the analysis phase, the incompatible codes were re-examined for consensus. In this context, it can be said that the content analysis carried out in the research is reliable.

\section{Findings}

\section{Change by years and citation numbers}

According to Figure 1, when the number of studies by year and the number of citations to related studies is examined, it can be said that there is an increasing research trend regarding the concept of digital reading. With the increase of digital readings in the life of individuals, it can be interpreted as a common situation that the number of studies on the subject increases in direct proportion. 

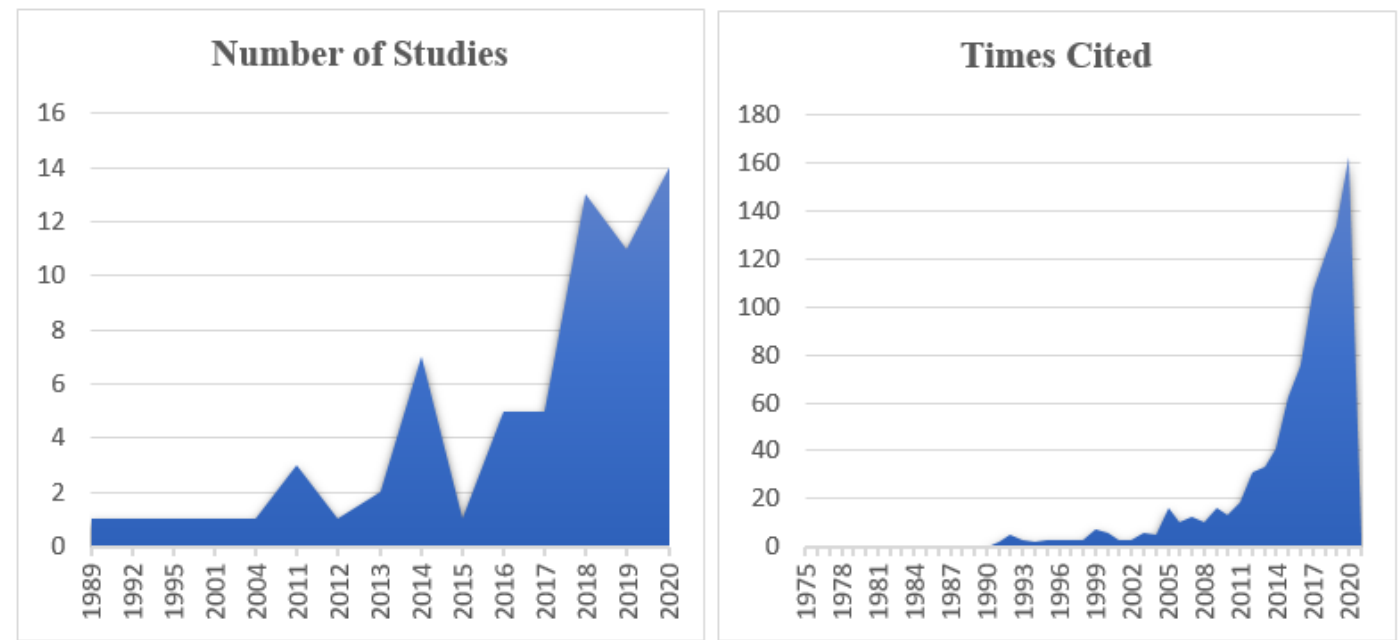

Figure 1. Change by years and citation numbers

\section{Number of studies by country}

According to Table 1, USA (29,5\%), Germany $(8,4 \%)$, Norway $(8,4 \%)$ and Australia $(7.0 \%)$ stood out when the eligible studies were examined by country.

Table 1. Number of Studies (only countries with more than one study are included in the table)

\begin{tabular}{lllllllll}
\hline Country & $\mathbf{n}$ & $\mathbf{f}(\boldsymbol{\%})$ & Country & $\mathbf{n}$ & $\mathbf{f}(\boldsymbol{\%})$ & Country & $\mathbf{f}$ & $\mathbf{f}(\boldsymbol{\%})$ \\
\hline USA & 21 & 29,5 & Netherlands & 4 & 5,6 & South Korea & 3 & 4,2 \\
Germany & 6 & 8,4 & Spain & 4 & 5,6 & Finland & 2 & 2,8 \\
Norway & 6 & 8,4 & Taiwan & 4 & 5,6 & France & 2 & 2,8 \\
Australia & 5 & 7,0 & Canada & 3 & 4,2 & China & 2 & 2,8 \\
Israel & 4 & 5,6 & England & 3 & 4,2 & Turkey & 2 & 2,8 \\
\hline
\end{tabular}

In this table, countries with two or more studies on the subject are included. USA is one of the leading countries in the world in technology. Access to technology and increased use of digital resources have led to an increase in digital reading efforts. The U.S. population and the large number of students are considered to be proportional to the number of studies. Another notable finding is that studies are usually conducted in developed countries.

\section{Participants and socio-economic level}

As shown in Table 2, when the distribution of the studies by participants was examined, it is seen that most of the studies were carried out with K-12 (47,76\%) level followed by higher education $(29,85 \%)$ level. It can be said that about half of the examined studies were carried out with students at K-12 level.

Table 2. Participants

\begin{tabular}{lll}
\hline Participants & n & $\mathbf{f ( \% )}$ \\
\hline K-12 & $\mathbf{3 2}$ & $\mathbf{4 7 , 7 6}$ \\
10th graders & 10 & 14,93 \\
10th grader with dyslexia & 1 & 1,49 \\
5th graders & 7 & 10,45 \\
6th graders & 6 & 8,96 \\
4th graders & 2 & 2,99 \\
\hline
\end{tabular}




\begin{tabular}{lll}
\hline 2nd graders & 2 & 2,99 \\
8th graders & 1 & 1,49 \\
7th graders & 1 & 1,49 \\
3rd graders & 1 & 1,49 \\
Grades 1-9 -general k-12 & 1 & 1,49 \\
Higher education & $\mathbf{2 0}$ & $\mathbf{2 9 , 8 5}$ \\
Undergraduate & 15 & 22,39 \\
Graduate & 4 & 5,97 \\
Undergraduate dyslexia & 1 & 1,49 \\
Preschool child & $\mathbf{1 0}$ & $\mathbf{1 4 , 9 3}$ \\
36-60 months & 9 & 13,43 \\
24-36 months & 1 & 1,49 \\
Adults & $\mathbf{4}$ & $\mathbf{5 , 9 7}$ \\
Parents & 3 & 4,48 \\
Caregivers & 1 & 1,49 \\
Instructor & $\mathbf{1}$ & $\mathbf{1 , 4 9}$ \\
\hline
\end{tabular}

In most of the examined studies, no information about the socio-economic level was found. In the studies mentioned, as shown in Table 3, it was determined that most of the participants had low-to-medium socioeconomic level $(38,5 \%)$ followed by medium-high socioeconomic level $(30,7 \%)$.

Table 3. Socio-economic level of participants

\begin{tabular}{lll}
\hline Status & n & $\mathbf{f ( \% )}$ \\
\hline Low-middle socioeconomic status & 5 & 38,5 \\
Medium-high socioeconomic status & 4 & 30,7 \\
Low socioeconomic status & 2 & 15,4 \\
Middle socioeconomic status & 2 & 15,4 \\
\hline
\end{tabular}

Research has a high tendency to work with lower-to-medium socioeconomic groups. At a time of evolution from printed books to electronic books, it can be considered as an expected situation to be carried out in socio-economically disadvantaged groups that address digital reading.

\section{Methodologies used in studies}

Table 4 provides data on the methodological trend in the studies examined. Accordingly, it was seen that experimental-semi-experimental and correlational research types were mostly preferred.

Table 4. Methodologies used in studies

\begin{tabular}{lll}
\hline Methodologies & n & $\mathbf{f ( \% )}$ \\
\hline Experimental / semi-experimental research & 16 & 29,1 \\
Correlational research & 15 & 27,2 \\
Survey & 11 & 20,0 \\
Qualitative research & 8 & 14,5 \\
Mixed research & 3 & 5,5 \\
Action research & 1 & 1,8 \\
Reflection papers & 1 & 1,8 \\
\hline
\end{tabular}


The studies using correlation and regression analysis were considered within the type of correlational research. In the examined studies, the excess of studies with these species is noted. The main conclusion that can be traced by looking at the methods used in the research is that the studies were carried out mainly with quantitative patterns. Although studies carried out according to qualitative research patterns existed, it was found to be in limited numbers.

\section{Reading types, methods, techniques and tools in studies}

Table 5 reports the reading types, methods, techniques and tools used in the examined studies. As shown in Table 5, digital shared reading (22,72\%), explanatory and narrative texts $(9,09 \%)$, hypermedia document based $(9,09 \%)$, story computer based $(9,09 \%)$ were the most commonly used strategies/approaches in the context of reading types, methods, techniques and tools.

Table 5. Reading type, method, technique and tools

\begin{tabular}{lll}
\hline Reading style & $\mathbf{n}$ & $\mathbf{f}(\mathbf{\%})$ \\
\hline Digital shared reading & 5 & 22,72 \\
Explanatory and narrative texts & 2 & 9,09 \\
Hypermedia document based & 2 & 9,09 \\
Story computer based & 2 & 9,09 \\
Collaborative reading & 1 & 4,54 \\
Icon digital texts & 1 & 4,54 \\
Leisure reading & 1 & 4,54 \\
Long-text reading & 1 & 4,54 \\
Interactive shared book reading & 1 & 4,54 \\
Interactive picture books reading & 1 & 4,54 \\
Reading aloud & 1 & 4,54 \\
Reading storybooks & 1 & 4,54 \\
Short texts & 1 & 4,54 \\
Dialogic reading & 1 & 4,54 \\
Digital and text print & 1 & 4,54 \\
\hline
\end{tabular}

It has been observed that digital shared reading is used more in terms of reading methods. Shared reading includes joint reading, interactive shared reading and dialogic reading. Again, studies comparing reading performance (e.g., comprehension) according to different types of texts stand out in number.

\section{Variables in studies (dependent-independent)}

Table 6 reports data on the variables used in the examined studies. When Table 6 is examined, it is seen that reading comprehension (10\%) was the most commonly investigated variable followed by reading achievement $(4,66 \%)$, vocabulary learning $(4,66 \%)$, gender $(3,33 \%)$, navigation $(3,33 \%)$ and reading time $(3,33 \%)$.

Table 6. Variables

\begin{tabular}{llllcl}
\hline Variables & $\mathbf{n}$ & $\mathbf{f}(\boldsymbol{\%})$ & Variables & $\mathbf{n}(\boldsymbol{\%})$ \\
\hline Reading comprehension & 15 & 10,0 & High frequency words & 1 & 0,66 \\
Reading achievement & 7 & 4,66 & Immigrant status & 1 & 0,66 \\
Vocabulary learning & 7 & 4,66 & $\begin{array}{l}\text { Intentional and unintentional } \\
\text { mind-wandering rate }\end{array}$ & 1 & 0,66 \\
Gender & 5 & 3,33 & Interactive book & 1 & 0,66 \\
\hline
\end{tabular}




\begin{tabular}{|c|c|c|c|c|c|}
\hline Navigation & 5 & 3,33 & $\begin{array}{l}\text { Interactive discussion scaffold } \\
\text { (raids) }\end{array}$ & 1 & 0,66 \\
\hline Reading time & 5 & 3,33 & Knowledge of reading strategies & 1 & 0,66 \\
\hline Socio-economic status & 4 & 2,66 & Legibility & 1 & 0,66 \\
\hline Internet connection & 3 & 2,00 & Leisure reading & 1 & 0,66 \\
\hline Reading motivation & 3 & 2,00 & Linear reading & 1 & 0,66 \\
\hline Reading skills & 3 & 2,00 & Medium preferences & 1 & 0,66 \\
\hline Attitudes toward ICT & 2 & 1,33 & Metacognitive knowledge & 1 & 0,66 \\
\hline Digital reading competency & 2 & 1,33 & Meta-comprehension & 1 & 0,66 \\
\hline Dyslexic & 2 & 1,33 & Modality of reading formats & 1 & 0,66 \\
\hline Independent reading & 2 & 1,33 & Parental education level & 1 & 0,66 \\
\hline Literacy development & 2 & 1,33 & Parental pressure & 1 & 0,66 \\
\hline Metacognitive strategies & 2 & 1,33 & Parent-child interaction & 1 & 0,66 \\
\hline Online reading habits & 2 & 1,33 & $\begin{array}{l}\text { Parents' attitudes towards and } \\
\text { beliefs }\end{array}$ & 1 & 0,66 \\
\hline Reading ability & 2 & 1,33 & Perceptions & 1 & 0,66 \\
\hline Reading assessment & 2 & 1,33 & Reading aloud & 1 & 0,66 \\
\hline Self-regulated learning & 2 & 1,33 & Reading attitude & 1 & 0,66 \\
\hline A digital pedagogical agent & 1 & 0,66 & comprehension & 1 & 0,66 \\
\hline Active decoding & 1 & 0,66 & Reading engagement & 1 & 0,66 \\
\hline Age & 1 & 0,66 & Reading enjoyment & 1 & 0,66 \\
\hline $\begin{array}{l}\text { Attitudes toward foreign language } \\
\text { learning }\end{array}$ & 1 & 0,66 & Reading fluency & 1 & 0,66 \\
\hline $\begin{array}{l}\text { Augmented reality (AR) mobile game } \\
\text { and a printed game }\end{array}$ & 1 & 0,66 & Reading preferences & 1 & 0,66 \\
\hline Basic computer skills & 1 & 0,66 & Reading stamina & 1 & 0,66 \\
\hline Children's language development & 1 & 0,66 & $\begin{array}{l}\text { Reading strategies } \\
\text { metacognitive awareness }\end{array}$ & 1 & 0,66 \\
\hline Children's technology experience & 1 & 0,66 & School choice & 1 & 0,66 \\
\hline $\begin{array}{l}\text { Collaborative reading annotation } \\
\text { system (cras) }\end{array}$ & 1 & 0,66 & Self-evaluations & 1 & 0,66 \\
\hline $\begin{array}{l}\text { Competency in computer and other } \\
\text { digital devices }\end{array}$ & 1 & 0,66 & Shared reading & 1 & 0,66 \\
\hline Computer usage habits & 1 & 0,66 & Sight word & 1 & 0,66 \\
\hline Computerized reading program & 1 & 0,66 & Social online reading activities & 1 & 0,66 \\
\hline Cost & 1 & 0,66 & $\begin{array}{l}\text { Student acceptance of e-text } \\
\text { books }\end{array}$ & 1 & 0,66 \\
\hline Cultural capital & 1 & 0,66 & Student engagement & 1 & 0,66 \\
\hline Dialogic reading & 1 & 0,66 & Student learning outcomes & 1 & 0,66 \\
\hline Digital literacy games & 1 & 0,66 & Task difficulty & 1 & 0,66 \\
\hline Digital reading for pleasure & 1 & 0,66 & Text length & 1 & 0,66 \\
\hline Digital reading proficiency & 1 & 0,66 & Time spent on academic reading & 1 & 0,66 \\
\hline $\begin{array}{l}\text { Digitally combined reading/listening } \\
\text { experience }\end{array}$ & 1 & 0,66 & Typical readers & 1 & 0,66 \\
\hline Distraction talk & 1 & 0,66 & $\begin{array}{l}\text { Usability of interactive } \\
\text { whiteboards vs. Computers }\end{array}$ & 1 & 0,66 \\
\hline E-book reading frequency & 1 & 0,66 & Use of cognitive strategies & 1 & 0,66 \\
\hline Emergent story understanding & 1 & 0,66 & Use of ICT & 1 & 0,66 \\
\hline
\end{tabular}




\begin{tabular}{|c|c|c|c|c|c|}
\hline Evaluating online information & 1 & 0,66 & $\begin{array}{l}\text { Use of reading strategy in an } \\
\text { active reading context }\end{array}$ & 1 & 0,66 \\
\hline Experience of use of computer & 1 & 0,66 & $\begin{array}{l}\text { Verbal and multisensory } \\
\text { engagement }\end{array}$ & 1 & 0,66 \\
\hline $\begin{array}{l}\text { Extracurricular student experience } \\
\text { online }\end{array}$ & 1 & 0,66 & Visibility & 1 & 0,66 \\
\hline $\begin{array}{l}\text { Functional connectivity of the } \\
\text { cognitive control network }\end{array}$ & 1 & 0,66 & WebQuest-based teaching & 1 & 0,66 \\
\hline Grades & 1 & 0,66 & & & \\
\hline
\end{tabular}

Although reading may seem like a cognitive action; it can be considered that the sensory characteristics of reading such as attitude, anxiety and motivation may also be important in the reading process. In the studies examined, it is seen that the variables for measuring sensory characteristics are limited (e.g., reading motivation).

\section{The most used terms in the abstract sections}

VOSviewer software was used to establish the most used terms in the abstract sections. In this context, the bibliometric data file obtained from the Web of Science (WOS) database was uploaded to VOSviewer software. In the analysis, the minimum number of occurrences of a term was 5 , and the full counting method was used in the relevant analysis and a total of 89 words were found. Of these, the highest 60 percent, or 53, were mapped according to their relevance scores. The map created by the program is included in Figure 2

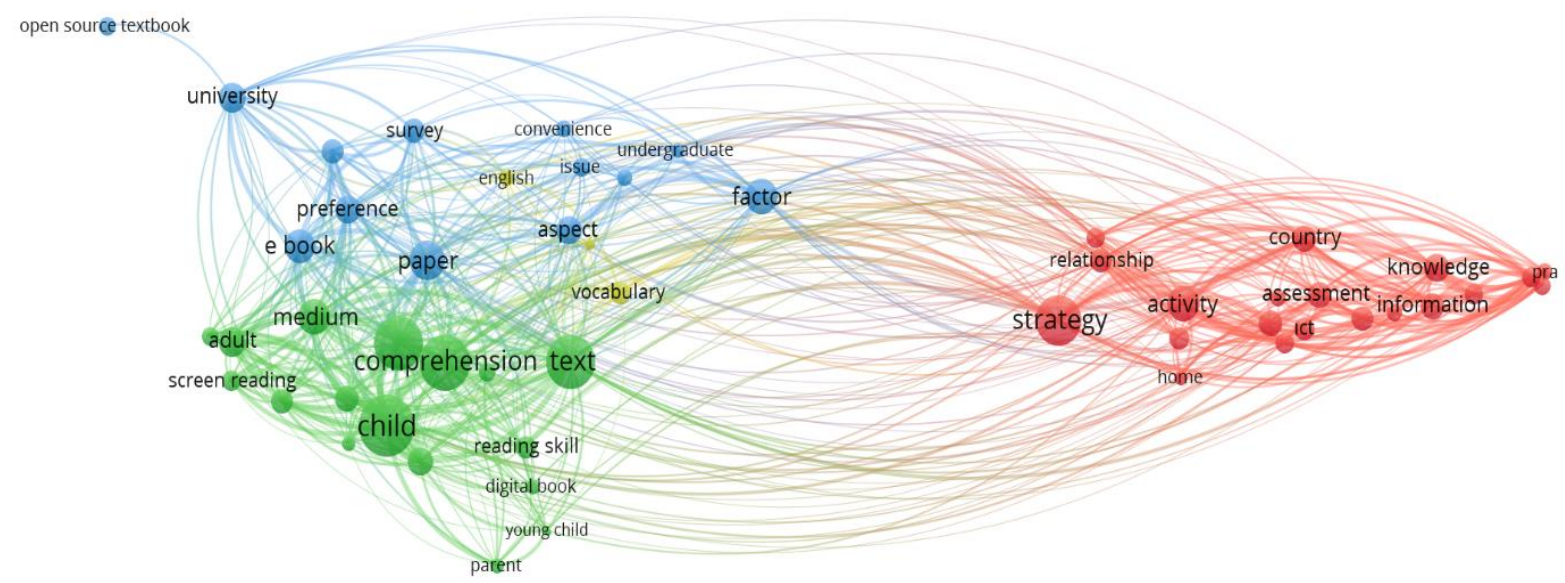

Figure 2. The most used terms in the abstract sections

When Figure 2 is examined, it is seen that 4 subsets appear. The most commonly used concepts by figure are, respectively; child $(\mathrm{f}=62)$, text $(\mathrm{f}=42)$, comprehension $(\mathrm{f}=36)$, book $(\mathrm{f}=35)$, and strategy $(\mathrm{f}=31)$. Based on these findings, it indicates that the studies examined concentrate on the effect of strategy use in reading texts or books in children. One of the most important elements in reading is comprehension. Digital reading studies also show a strong focus on comprehension. Again, it can be commented that digital reading is studied more in children.

\section{The most used author keywords}

The options of co-occurrence and author keywords were used together to identify the most commonly used keywords created by the author. In the relevant analysis, the minimum 
number of keywords was 2 and the number of keywords to be selected was 30. The map created (Figure 3 ) is below.

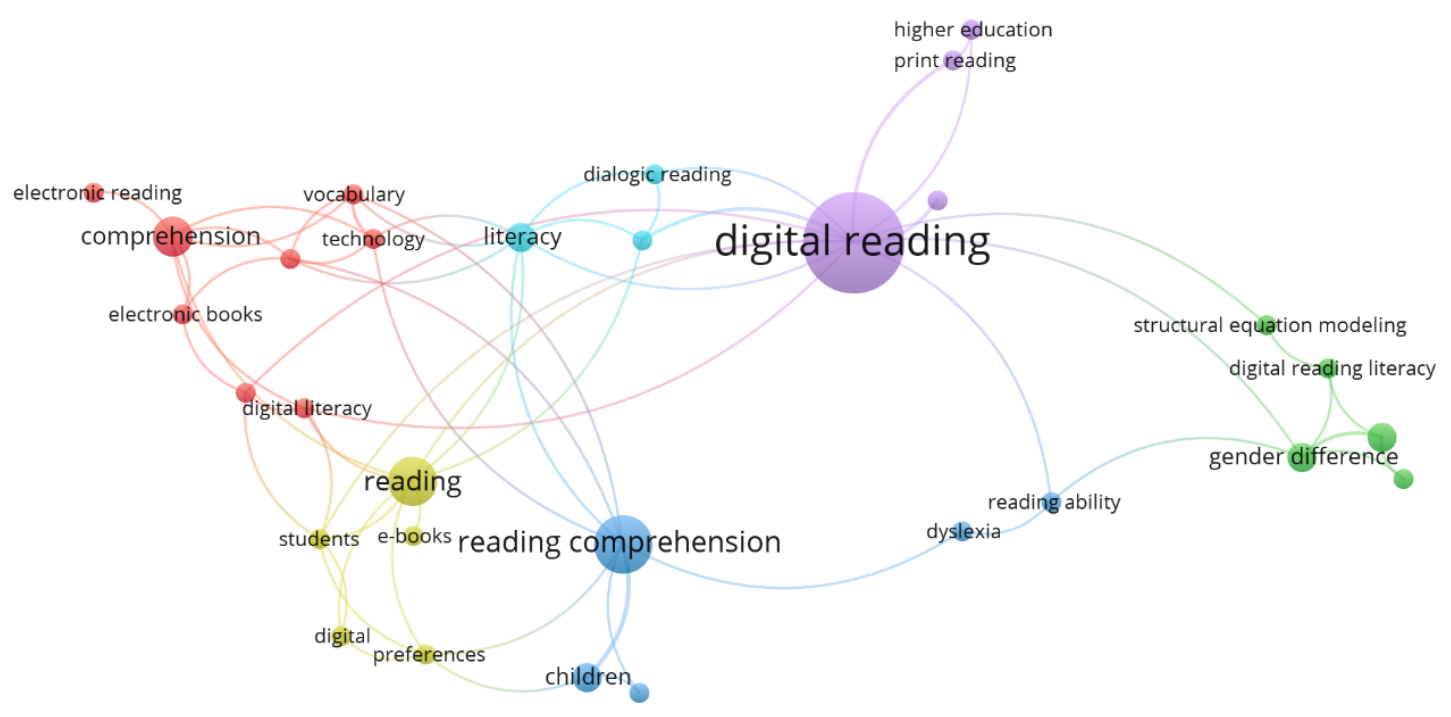

Figure 3. The most used author keywords

When Figure 3 is examined, the most commonly used keywords are, respectively; digital reading $(\mathrm{f}=11)$, reading comprehension $(\mathrm{f}=6)$, reading $(\mathrm{f}=5)$, comprehension $(\mathrm{f}=4)$, literacy $(\mathrm{f}=3)$, and gender difference $(\mathrm{f}=3)$. These results show that studies focus more on reading comprehension, literacy and gender differences.

\section{References/authors with the most references in the relevant literature}

The network chart of the most cited authors/references in the field is presented below. Co-citation analysis and authors (cited-authors) options were used together to obtain the graph, and references/authors with at least 10 citations were included in the analysis. In this case, a total of 13 references/authors were included in the network chart. The created map is provided in Figure 4.

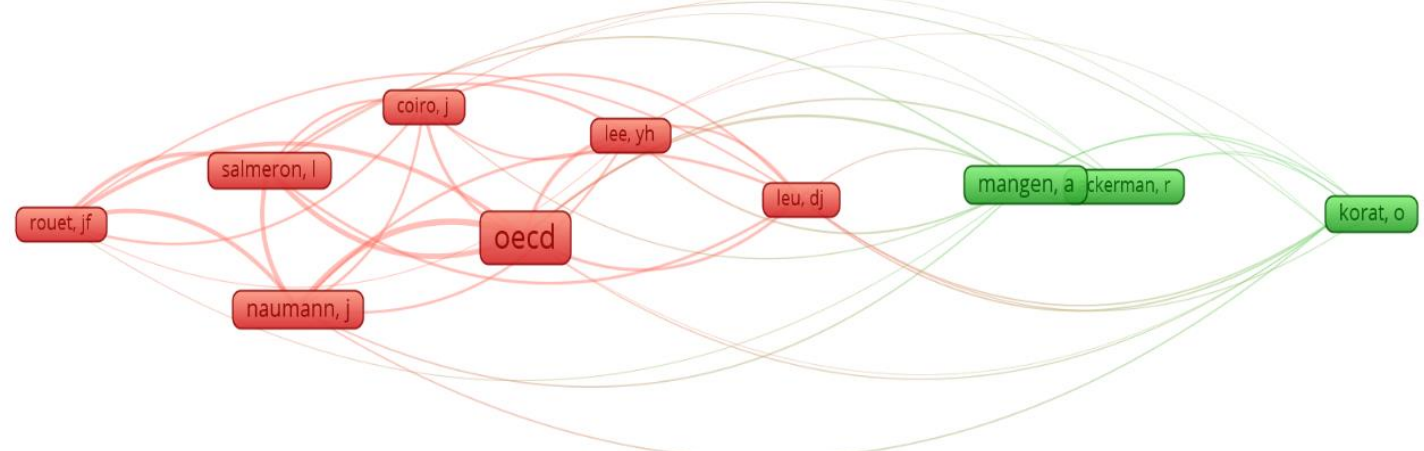

Figure 4. References/authors with the most references in the relevant literature

When Figure 4 is examined, the references/authors most commonly cited in digital reading studies are as follows: OECD ( $\mathrm{f}=46)$, Naumann, $\mathrm{J}(\mathrm{f}=24)$, Mangen, A ( $\mathrm{f}=21)$, Salmeron, I $(\mathrm{f}=20)$, Korat, $\mathrm{O}(\mathrm{f}=17)$, Bus, AG ( $\mathrm{f}=16)$, Leu, DJ $(\mathrm{f}=14)$, Ackerman, $\mathrm{R}(\mathrm{f}=13)$, Rouet, JF $(\mathrm{f}=12)$, Coiro, J $(\mathrm{f}=12)$, Senechal, $\mathrm{M}(\mathrm{f}=12)$, Lee, $\mathrm{YH}(\mathrm{f}=12)$ and Horowitz-Kraus, $\mathrm{T}(\mathrm{f}=10)$. The OECD is the most frequently cited reference in the studies. This is because the variable 
"digital reading performance (DRA)" has been analyzed in the Programme for International Student Assessment (PISA) in recent years (OECD, 2012).

\section{Discussion and conclusion}

This research aims to determine the trends and prominent concepts/topics in digital reading by examining the studies in a systematic and holistic manner. For this purpose, content analysis, descriptive and bibliometric analyses were used in the research.

In the study, the changes of the studies in the research sample according to the years and citation numbers were examined. When the number of studies in the sample is examined, it is noticeable that there has been a significant increase in numerical numbers, especially in recent years (in 2018, 2019 and 2020). An increasing number of digital reading devices versus printed books lead to a transition from print to screen reading (Mangen et al., 2013). The fact that technology is more involved in people's daily lives has increased the time spent with digital screens. This may also increase the trend towards digital reading.

In this context, it is thought that the increase in the number of studies on the subject is due to the change in the reading format and the desire to examine the effects and components related to the subject owing to the differentiating structure of the digital reading format.

In the study, it was determined that digital reading studies are usually carried out in developed countries. The Internet and other technologies are an important tool in preparing children for their future in the information age. For this purpose, developed countries such as "Australia, Finland, Ireland, New Zealand, the United Kingdom, and the United States" integrate new technologies into their classrooms with internet-connected computers, appropriate software, ICT compliance curriculum and technology-proficient teachers (International Reading Association (IRA), 2009). All these developments indicate that digitalization is not ignored in literacy. Therefore, it can be said that digital reading is the source of in-class reading activity orientations in different countries and has become the subject of academic studies. However, it can be said that further studies on digital reading in developed countries have an impact on the technology-oriented planning that these countries use in their educational environments.

When the studies were reviewed, it was seen that the highest number of studies was carried out at the level of K-12. However, it was determined that the tenth graders were mainly involved in the studies and this group was followed by the sixth and fifth graders. In this case, the fact that the data group is usually performed with the tenth grades can be seen as an important factor in PISA reports. There is a growing trend towards the presentation of universal assessment exams in digital format (Eyre, Berg, Mazengarb \& Lawes, 2017; Støle, Mangen, Frønes \& Thomson, 2018) and the preparation of a separate assessment for digital reading in PISA (OECD, 2012) may be other reasons for this. In research with university students, it can be said that the subject of reading format preference (print or digital) has come to the forefront more (Johnston \& Salaz, 2019; Pesut \& Zivkovic, 2016; Pinto et al., 2014; Stoller \& Nguyen, 2020).

Another noteworthy point in the participant group is that the 2-3 age group is also involved in digital reading studies. The formation of technology experiences of children from a very early age is a strong reason for more empirical studies on digital reading in the future. In addition, it should be taken into account that children who read shared books from an early age may have higher success in language, reading and spelling in the future (Mol \& Bus, 2011), in this context, parent-child "co-reading" activities can be increased in preschool with the help of digital reading tools (Krcmar \& Cingel, 2014). A study of 1,400 parents whose children were 
up to 8 years old found that almost all children had some kind of mobile device and television in their home, $95 \%$ of their parents owned smartphones and $42 \%$ had their own tablet devices (Rideout, 2017). Today's children are the most technologically experienced generation among children who start school for reading education (Blanchard \& Farstrup, 2011, p.286). With the early encounter with digital tools, digital reading experiences are also increasing. This situation has been investigated in different studies; the effect of electronic books on the understanding of stories that develop in preschool children (De Jong \& Bus, 2004), understanding printed or digital books of preschool children, comparing vocabulary and engagements (Reich, Yau, Xu, Muscat, Uvalle \& Cannata, 2019), the effect of different reading techniques on the language development of preschoolers (Şimşek \& Erdoğan, 2020).

In the present study, it was determined that the participants in the relevant research had a lower-to-medium socioeconomic level. Many studies have observed positive correlations between socio-economic level and literacy development (Rasmusson, 2016). In other words, high socio-economic level is associated with more successful reading performance in reading studies. This situation can be examined from different angles, but basically the cost of reading format preference may be an important variable in digital reading studies (Mizrachi, Salaz, Kurbanoglu, \& Boustany, 2018; Tosun, 2014). Instead of asking students to read printed versions of articles or book chapters, educational institutions send them a digital version of the material online. This leads to easy access to materials, while on the other hand, it leads to the increasing growth of online learning. Cost savings related to reading materials also create a motivation for user preferences (Baron et al., 2017). In his research with university students, Mizrachi (2015) shows that the vast majority of students prefer to read in print over electronic reading. However, factors such as accessibility and cost have also been found to affect their actual behavior.

When the studies in the research sample were examined, it was seen that methods were preferred in more experimental-semi-experimental and correlational research types. In this context, it can be said that quantitative patterns are preferred in studies, and there are fewer studies in qualitative research type. This may have been caused by studies comparing digital reading and print reading in the sample.

In the analysis process through which the most commonly used variables in the studies, the most used concepts in the abstract sections or the most used keywords by the author were examined, it was seen that the concept of reading comprehension came to the forefront. However, reading achievement and vocabulary learning were also found to be studied more than other variables. That said, when looking at the variables used in the studies holistically, it was observed that 93 different variables were studied in digital reading studies. This suggests that digital reading is just as complex as traditional print reading (Liu, 2005). In the studies examined, it is seen that the variables for measuring sensory characteristics are limited (e.g., reading motivation). In a limited number of studies examining the effect of reading format on reading motivation, it was concluded that reading from the screen gave significantly lower results in terms of reading motivation (Aydemir \& Öztürk, 2012) or did not make a meaningful difference (Wells, 2012).

In the bibliometric analysis findings carried out in the study, comprehension, text, book, child, strategy, and activity concepts are among the most commonly used concepts in the abstract sections of the studies in the sample. Apart from the concepts such as text, book, child, which are expected to be seen prominently as a result of bibliometric analysis, comprehension, strategy and activity are important concepts that stand out. The findings also support the 
argument expressed by Liu (2012), pointing out that digital reading requires the implementation of some strategies that are not included in traditional print reading. However, the concept of comprehension mentioned in previous findings is the most important issue for digital reading. In human daily life which is becoming increasingly digital in the internet of things age, an increased importance of reading from the screen in many areas is witnessed. In fact, in today's world wrapped in digital tools, understanding what is read has become an activity of understanding the environment. However, it is known that long-term screen use in preschool children can cause structural limitations in the organization of brain white matter, which supplements language and literacy activities (Hutton, Dudley, Horowitz-Kraus, DeWitt \& Holland, 2020). In this context, it is clear that the subject of comprehension in digital reading should continue to be supported by multidimensional experimental studies.

When the types, methods and techniques of reading in the studies were examined, it was seen that more digital shared reading strategies were used in digital reading studies. Shared reading includes joint reading, interactive shared reading and dialogic reading types. The shared reading strategy is to read a large book or an extended text by sharing it with a group of children or the whole class (Vacca et al., 2015, p.104). Studies have shown that digital shared reading strategies are often carried out with children's parents or teachers. Joint reading activities with families are the most researched and best-known family-child activities in the western culture (Kucirkova \& Flewitt, 2020). However, it is known that joint reading activities with co-parents or teachers promote the development of language and literacy in children (Bus, Van Ijzendoorn \& Pellegrini, 1995). Another conclusion obtained in the research is that studies comparing reading performance (e.g., comprehension) by different types of text (informative or narrative text) stand out in number. All these results indicate that digital reading studies focus on the effect of the use of reading strategies on reading comprehension.

In the sampled studies, when "author keywords" were examined, it was determined that the most commonly used concepts were digital reading, reading comprehension, reading, comprehension, literacy and gender difference, respectively. Other than digital reading, reading, and literacy, which are possible expected concepts in bibliometric analysis, there have been prominent keywords such as comprehension and gender. The concept of reading comprehension, which has appeared frequently in previous findings in the study, is also frequently used in "author keywords". Another common concept is gender. Gender is thought to be an important variable in digital reading studies (Cheung, Mak \& Sit 2013; Zhan, Wu, Mei, Wu \& Fong, 2020). In this context, it should be considered that girls and boys can perform differently in empirical studies on digital reading.

When the authors/references that received the most references in the field were examined, it was determined that the OECD reports were among the most preferred references that were cited. Digital reading performance (DRA) was tested by PISA 2009 as a dependent variable that assesses students' digital reading competencies and knowledge (OECD, 2012). Studies have also shown that this variable and therefore the OECD are the frequently referred sources. Digital reading is a new field of study. With digitalization, the increase of readings from digital sources is the starting point for this work to be carried out. In the study, it was seen that there has been an increase in the number of studies on digital reading in recent years and that the studies are mostly carried out in developed countries. Among the reasons for this situation may be the increase in technology integration into educational activities in developed countries and the fact that the socio-economic level of developed countries is better than in other countries. One of the conditions observed in the examined studies is frequent 
comparisons of paper based and digital based reading $(69,09 \%)$. Also, reading formats were more compared in terms of variables such as reading comprehension and reading motivation. Reasons for the aforementioned comparisons may be that; readers are not very familiar with the digital reading format, there are non-text elements in the digital reading process, and readers are not adequately equipped for digital reading strategies. When the most commonly used variables, the concepts most used in abstract sections or the most commonly used keywords created by the author were examined, it was seen that reading comprehension variable/term came to the fore. The essence of reading is the understanding of what is read, that is, comprehension. Apart from this variable, future research may focus on other reading components such as fluency, speed, prosody in digital reading or to determine the sensory characteristics of reading such as motivation, anxiety and attitude. In addition, there are many methods and techniques for reading in the literature. In the study, "shared reading", the most commonly used reading method, is just one of them. In future digital reading studies, the effect of different reading methods and techniques on reading success can be focused.

\section{Significance and limitations}

With digital tools and the internet surrounding the lives of individuals from a very young age, it can be considered that theoretical frameworks and approaches working against the background of traditional paper-based reading activities can differ in the context of digital/screen reading activities. In this direction, the examination of different dimensions and components related to digital reading studies and reaching a detailed perspective in this direction can be seen as important for the relevant literature. This research aims to define research trends, methods and various aspects related to the concept of digital reading. Accordingly, it is thought that the study can provide a detailed perspective to the researchers, experts and teachers working in the relevant field. However, there are some limitations in this particular study. The first limitation is about the database used. Accordingly, other databases may also list different original studies on the subject. Also, it is noticeable that there are over twenty thousand studies in the Google Academic database related to the subject area. This makes it very difficult to analyze those individual studies in detail. However, this research aims to examine high-quality studies scanned on the Web of Science Core Cortex. This also hinders the analysis of those individual studies in detail. The other issue seen as limitation in this study is the inclusion of peer reviewed studies written only in English. In line with this criteria, conference papers and book chapters that may not have gone through a peer-review process are not included in the scope of the study.

\section{References}

Ackerman, R., \& Goldsmith, M. (2011). Metacognitive regulation of text learning: On screen versus on paper. Journal of Experimental Psychology: Applied, 17(1), 18-32. https://doi.org/10.1037/a0022086

Aydemir, Z., \& Ozturk, E. (2012). The effects of reading from the screen on the reading motivation levels of elementary 5th graders. Turkish Online Journal of Educational Technology-TOJET, 11(3), 357-365.

Aydemir, Z., Öztürk, E., \& Horzum, M. B. (2013). The effect of reading from screen on the 5 th grade elementary students' level of reading comprehension on informative and narrative type of texts. Educational Sciences: Theory and Practice, 13(4), 2272-2276. https://doi.org/10.12738/estp.2013.4.1294 
Baron, N. S. (2020). Digital reading: A research assessment. In E.B. Moje, P. Afflerbach, P. Enciso, \& N.K. Lesaux (Eds.), Handbook of reading research volume V. (p.116-136). New York and London: Routledge.

Baron, N. S., Calixte, R. M., \& Havewala, M. (2017). The persistence of print among university students: An exploratory study. Telematics and Informatics, 34(5), 590-604. https://doi.org/10.1016/j.tele.2016.11.008

Blanchard, J. S., \& Farstrup, A. E. (2011). Technologies, digital media, and reading instruction. In S.J. Samuels, \& A.E. Farstrup (Eds.), What research has to say about reading instruction (4th ed.) (p. 286-314). Newark, DE: International Reading Association.

Bus, A. G., Van Ijzendoorn, M. H., \& Pellegrini, A. D. (1995). Joint book reading makes for success in learning to read: A meta-analysis on intergenerational transmission of literacy. Review of Educational Research, 65(1), 1-21. https://doi.org/10.3102/00346543065001001

Chen, C. M., \& Chen, F. Y. (2014). Enhancing digital reading performance with a collaborative reading annotation system. Computers \& Education, 77, 67-81. https://doi.org/10.1016/j.compedu.2014.04.010

Chen, G., Cheng, W., Chang, T. W., Zheng, X., \& Huang, R. (2014). A comparison of reading comprehension across paper, computer screens, and tablets: Does tablet familiarity matter?. Journal of Computers in Education, 1(2), 213-225. https://doi.org/10.1007/s40692-014-0012-z

Cheung, K. C., Mak, S. K., \& Sit, P. S. (2013). Online reading activities and ICT use as mediating variables in explaining the gender difference in digital reading literacy: Comparing Hong Kong and Korea. The Asia-Pacific Education Researcher, 22(4), 709-720. https://doi.org/10.1007/s40299-013-0077-x

Clinton, V. (2019). Reading from paper compared to screens: A systematic review and metaanalysis. Journal of Research in Reading, 42(2), 288-325. https://doi.org/10.1111/1467-9817.12269

Cull. B. W. (2011). Reading revolutions: Online digital text and implications for reading in academe. First Monday, 16(6). https://doi.org/10.5210/fm.v16i6.3340

De Jong, M. T., \& Bus, A. G. (2004). The efficacy of electronic books in fostering kindergarten children's emergent story understanding. Reading Research Quarterly, 39(4), 378-393. https://doi.org/10.1598/RRQ.39.4.2

Delgado, P., Vargas, C., Ackerman, R., \& Salmerón, L. (2018). Don't throw away your printed books: A meta-analysis on the effects of reading media on reading comprehension. Educational Research Review, 25, 23-38. https://doi.org/10.1016/j.edurev.2018.09.003

Denyer, D., \& Tranfield, D. (2009). Producing a systematic review. In D. A. Buchanan \& A. Bryman (Eds.), The Sage handbook of organizational research methods (p. 671-689). Sage Publications Ltd.

Eyre, J., Berg, M., Mazengarb, J., \& Lawes, E. (2017). Mode equivalency in PAT: Reading comprehension. Wellington: NZCER. Retrieved from: http://www.nzcer.org.nz/system/files/PAT\%20Modes_report.pdf

Golan, D. D., Barzillai, M., \& Katzir, T. (2018). The effect of presentation mode on children's reading preferences, performance, and self-evaluations. Computers \& Education, 126, 346-358. https://doi.org/10.1016/j.compedu.2018.08.001

Hayles, N. K. (2010). How we read: Close, hyper, machine. ADE Bulletin, 150(18), 62-79.

Haddock, G., Foad, C., Saul, V., Brown, W., \& Thompson, R. (2020). The medium can influence the message: Print-based versus digital reading influences how people 
process different types of written information. British Journal of Psychology, 111(3), 443-459. https://doi.org/10.1111/bjop.12415

Hutton, J. S., Dudley, J., Horowitz-Kraus, T., DeWitt, T., \& Holland, S. K. (2020). Associations between screen-based media use and brain white matter integrity in preschool-aged children. JAMA Pediatrics, 174(1), e193869. https://doi.org/10.1001/jamapediatrics.2019.3869

International Reading Association. (2009). New literacies and 21st-century technologies: A position statement of the International Reading Association. Newark, DE. Retrieved from: https://www.literacyworldwide.org/docs/default-source/.where-we-stand/newliteracies-21st-century-position-statement.pdf?sfvrsn=6

Johnston, N., \& Salaz, A. M. (2019). Exploring the reasons why university students prefer print over digital texts: An Australian perspective. Journal of the Australian Library and Information Association, 68(2), 126-145. https://doi.org/10.1080/24750158.2019.1587858

Karchmer, R. A. (2008). The journey ahead: Thirteen teachers report how the Internet influences literacy and literacy instruction in their K-12. In J. Coiro, M. Knobel, C. Lankshear, \& D. J. Leu (Eds.), Handbook of research on new literacies (p. 12411280). New York: Routledge

Kerr, M. A., \& Symons, S. E. (2006). Computerized presentation of text: Effects on children's reading of informational material. Reading and Writing, 19(1), 1-19.

Krcmar, M., \& Cingel, D. P. (2014). Parent-child joint reading in traditional and electronic formats. Media Psychology, 262-281. https://doi.org/10.1080/15213269.2013.840243

Kucirkova, N., \& Flewitt, R. (2020). The future-gazing potential of digital personalization in young children's reading: views from education professionals and app designers. Early Child Development and Care, 190(2), 135-149. https://doi.org/10.1080/03004430.2018.1458718

Liu, Z. (2005). Reading behavior in the digital environment: Changes in reading behavior over the past ten years. Journal of Documentation. 61(6) https://doi.org/10.1108/00220410510632040

Liu, Z. (2012). Digital reading: An overview. Chinese Journal of Library and Information Science, 5(1), 85-94.

Loh, C. E., \& Sun, B. (2019). "I'd Still Prefer to Read the Hard Copy": Adolescents' Print and Digital Reading Habits. Journal of Adolescent \& Adult Literacy, 62(6), 663-672. https://doi.org/10.1002/jaal.904

Mangen, A., Walgermo, B. R., \& Brønnick, K. (2013). Reading linear texts on paper versus computer screen: Effects on reading comprehension. International Journal of Educational Research, 58, 61-68. https://doi.org/10.1016/j.ijer.2012.12.002

Margolin, S. J., Driscoll, C., Toland, M. J., \& Kegler, J. L. (2013). E-readers, computer screens, or paper: Does reading comprehension change across media platforms? Applied Cognitive Psychology, 27(4), 512-519. https://doi.org/10.1002/acp.2930

Miles, M. B., \& Huberman, A. M. (1994). Qualitative data analysis: An expanded sourcebook. (Second Edition). London: Sage.

Mizrachi, D. (2015). Undergraduates' academic reading format preferences and behaviors. The Journal of Academic Librarianship, 41(3), 301-311. https://doi.org/10.1016/j.acalib.2015.03.009

Mizrachi, D., Salaz, A. M., Kurbanoglu, S., and Boustany, J. (2018). Academic reading format preferences and behaviors among university students worldwide: a comparative survey analysis. PLoS One 13:e0197444. https://doi.org/10.1371/journal.pone.0197444 
Mol, S. E., \& Bus, A. G. (2011). To read or not to read: A meta-analysis of print exposure from infancy to early adulthood. Psychological Bulletin, 137(2), 267-296. https://doi.org/10.1037/a0021890

OECD (2012), PISA 2009 Technical Report, PISA, OECD Publishing. Retrieved from: https://www.oecd.org/pisa/pisaproducts/50036771.pdf

Pesut, D., \& Zivkovic, D. (2016). Students' academic reading format preferences in Croatia. New Library World, 117, 5/6, 392-406. https://doi.org/10.1108/NLW-02-2016-0008

Pinto, M., Pouliot, C., \& Cordón-García, J. A. (2014). E-book reading among Spanish university students. The Electronic Library. 32 (4), 473-492. https://doi.org/10.1108/EL-05-2012-0048

Porion, A., Aparicio, X., Megalakaki, O., Robert, A., \& Baccino, T. (2016). The impact of paper-based versus computerized presentation on text comprehension and memorization. Computers in Human Behavior, 54, 569-576. https://doi.org/10.1016/j.chb.2015.08.002

Rasmusson, M.A. (2016). A multilevel analysis of Swedish and Norwegian students' overall and digital reading performance with a focus on equity aspects of education. Largescale Assessment in Education, 4 (3), 1-25. https://doi.org/10.1186/s40536-016-00217-

Reich, S. M., Yau, J. C., Xu, Y., Muskat, T., Uvalle, J., \& Cannata, D. (2019). Digital or print? a comparison of preschoolers' comprehension, vocabulary, and engagement from a print book and an e-book. AERA Open, 5(3), 1-16. https://doi.org/10.1177/2332858419878389

Rideout, V. (2017). The Common Sense census: Media use by kids age zero to eight. Francisco, CA: Common Sense Media, 263-283. Retrieved from: https://www.commonsensemedia.org/sites/default/files/uploads/research/csm_zerotoei ght_fullreport_release_2.pdf

Singer, L. M., \& Alexander, P. A. (2017). Reading across mediums: Effects of reading digital and print texts on comprehension and calibration. The Journal of Experimental Education, 85(1), 155-172. https://doi.org/10.1080/00220973.2016.1143794

Støle, H., Mangen, A., \& Schwippert, K. (2020). Assessing children's reading comprehension on paper and screen: A mode-effect study. Computers \& Education, 151, 103861. https://doi.org/10.1016/j.compedu.2020.103861

Støle, H., Mangen, A., Frønes, T. S., \& Thomson, J. (2018). Digitisation of reading assessment. In M. Barzillai, J. Thompson, S. Schroeder, \& P. van den Broek (Eds.), Learning to read in a digital world (pp. 205-224). Amsterdam: John Benjamins Publishing Company

Stoller, F. L., \& Nguyen, L. T. H. (2020). Reading habits of Vietnamese University English majors. Journal of English for Academic Purposes, 48, 1-17. https://doi.org/10.1016/j.jeap.2020.100906

Şimşek, Z. C., \& Erdoğan, N. I. (2020). Comparing the effects of different book reading techniques on young children's language development. Reading and Writing. https://doi.org/10.1007/s11145-020-10091-9

Taylor, A. K. (2011). Students learn equally well from digital as from paperbound texts. Teaching of Psychology, 38(4), 278-281. https://doi.org/10.1177/0098628311421330

Tosun, N. (2014). A study on reading printed books or e-books: Reasons for student-teachers preferences. Turkish Online Journal of Educational Technology-TOJET, 13(1), 21-28.

Tveit, Å. K., \& Mangen, A. (2014). A joker in the class: Teenage readers' attitudes and preferences to reading on different devices. Library \& Information Science Research, 36(3-4), 179-184. https://doi.org/10.1016/j.lisr.2014.08.001 
Vacca, J. L., Vacca, R. T. Gove, M. K., Burkey, L. C., Lenhart, L. A., \& Mckeon, C. A. (2015). Reading \& learning to read. (9th Ed). Pearson Publication.

Van Eck, N., \& Waltman, L. (2010). Software survey: VOSviewer, a computer program for bibliometric mapping. Scientometrics, 84(2), 523-538.

Wells, C. L. (2012). Do students using electronic books display different reading comprehension and motivation levels than students using traditional print books?. (Unpublished doctoral dissertations), Liberty University.

Zhan, Z., Wu, J., Mei, H., Wu, Q., \& Fong, P. S. (2020). Individual difference on reading ability tested by eye-tracking: from perspective of gender. Interactive Technology and Smart Education, 17(3), 267-283. https://doi.org/10.1108/ITSE-12-2019-0082 